Chapter 12

\title{
Policing and Sentencing Practices in Russia and their Impacts on Women Who Use Drugs
}

\author{
Giavana Margo
}

\section{Introduction}

The Russian Federation is home to a significant population of people who use drugs (PWUD). It is estimated that there are 7.3 to 8.5 million PWUD in the country (US Department of State, 2019, p. 257). Moreover, Russia has one of the highest rates of injection drug use globally. Approximately 2.29 per cent of the adult population (aged 15-64) uses injection drugs, a rate well above the global average (United Nations Office on Drugs and Crime (UNODC), 2015a, p. 5). Putting this into perspective, according to the 2019 World Drug Report, nearly half of all people who inject drugs (PWID) reside in Russia, China and the United States (UNODC, 2019a, p. 19). The country's growing incidence of HIV is also strongly correlated to the high rates of injection drug use. Currently, Eastern and South-Eastern Europe account for 40 per cent of the global population of PWID living with HIV - a statistic due in part to the population of PWID living with HIV in Russia and Ukraine (UNODC, 2015a, p. 6). The primary route of HIV transmission in Russia continues to be injection drug use (Lunze et al., 2016, p. 1).

While high rates of injection drug use and HIV present a number of public health concerns, Russia's approach to drug policy is best described as one of 'social intolerance'. Russian law designates drug use as an administrative offence punishable by incarceration. Drug possession is classified as either an administrative or criminal offence, depending on quantities possessed, and is punishable by lengthy prison sentence (Code of Administrative Offences, 2001; Criminal

\footnotetext{
The Impact of Global Drug Policy on Women: Shifting the Needle, 113-121 Copyright $@ 2021$ by Giavana Margo These works are published under the Creative Commons Attribution (CC BY 4.0) licence. Anyone may reproduce, distribute, translate and create derivative works of these works (for both commercial and non-commercial purposes), subject to full attribution to the original publication and authors. The full terms of this licence may be seen at http://creativecommons.org/licences/by/4.0/legalcode doi:10.1108/978-1-83982-882-920200017
} 


\section{Giavana Margo}

Code, 1996). Beyond the legal framework, the 'societal ill treatment of PWUD' is encouraged among the public as well as across healthcare and criminal justice systems (Golichenko \& Chu, 2018, p. 2). This has resulted in the virtual absence of science-based drug treatment in Russia as well as significant social control by law enforcement (Golichenko \& Chu, 2018; Sarang, Rhodes, Sheon, \& Page, 2010). Recommended approaches for drug dependence treatment and care, such as substitution therapy, are illegal in the country and the limited treatment options that are available fall largely under the purview of law enforcement (Lunze et al., 2014, p. 1). Within this environment, PWUD are not treated as patients in need of health and social care but as criminals.

While laws around drug use and possession in Russia are by no means the harshest globally, amendments to existing policies and regulations, along with a lack of police accountability, have given law enforcement seemingly limitless power over PWUD. Such amendments have provided law enforcement agencies and courts with the liberty to mandate compulsory rehabilitation and drug treatment for PWUD (Golichenko \& Chu, 2018, p. 4). There is also evidence of frequent extrajudicial practices by police, such as planting drugs or arresting people for possession of drug paraphernalia (Lunze, Lunze, Raj, \& Samet, 2015; Sarang et al., 2010). It should be noted that carrying paraphernalia, such as needles or syringes, is not illegal in Russia. Extrajudicial arrests and practices extend beyond unwarranted arrests and coercion and into violence. A study conducted in Russia found that beatings and verbal harassment from police were common experiences for PWUD (Lunze et al., 2015). Such reports reveal the normalisation of violent and coercive police practices towards PWUD.

Globally, women are a minority within the population of PWUD. The 2015 World Drug Report found that in Russia specifically, women make up 30 per cent of those who inject drugs (UNODC, 2015a, p. 15). Despite being a minority, women now account for half of new HIV diagnoses in Russia, and across the region of Eastern Europe and Central Asia, the rates of HIV among women who inject drugs is escalating (El-Bassel, Wechsbert, \& Shaw, 2012; Lunze et al., 2014). Much of the research on drug use that employs a level of gender-based analysis has a public health focus and explores issues such as HIV risk factors for women who use drugs (WWUD) (i.e. Cepeda et al., 2011; Kozlov et al., 2006; Niccolai, Shcherbakova, Toussova, Kozlov, \& Heimer, 2009; Somlai et al., 2002; Yorick et al., 2012). Such studies have revealed that drug use behaviours themselves are gendered. For example, women tend to have riskier injection practices than men, often using with a male partner whom they share needles or syringes with, and they are less likely to be tested for HIV.

While there is increasing visibility and research on the experiences, realities and needs of WWUD in Russia, less is known about their interaction with the criminal justice system. This chapter, therefore, seeks to examine policing, sentencing and criminal justice practices towards women who use drugs, and their health and human rights impacts.

Data for this research was gathered through qualitative interviews conducted in 2019 with six key informants from different CSOs working on regional, national and local levels in Russia. CSO focus areas included HIV advocacy, 
harm reduction advocacy and service provision, drug policy reform and human rights. All CSOs had interactions with WWUD in Russia and provide a range of expertise on the topic. Interviews were conducted either in English or Russian based on the preference of the interviewees. Interviews were then transcribed and translated into English as needed. Data from the interviews were collected through thematic content analysis.

In addition to interviews, reports submitted to the United Nations (UN) Human Rights bodies and cases submitted to the European Court of Human Rights (ECHR) were also analysed and key themes identified. These include two CSO reports submitted to the Convention on the Elimination of all Forms of Discrimination Against Women (CEDAW), the report 'Pathways to, conditions and consequences of incarceration for women' submitted to the UN General Assembly by Special Rapporteur on violence against women, and two cases submitted to the ECHR (Bannikova vs Russia and Lagutin and others vs Russia).

\section{Findings}

During interviews, approaches to drug policy enforcement were discussed with particular attention to impacts on WWUD in Russia. A variety of topics arose during the interviews, but several were recurrent regarding the realities of women who use drugs. Similar key themes arose in the analysis of the UN reports and ECHR cases. These themes include repression and gender-based stigma; extrajudicial practices and violence from police towards women who use drugs; and bias within the broader criminal justice system. While health and social services were not the focus of discussion, the impact of the policy framework, including practices and conditions by police, courts and prisons, were frequently mentioned. For that reason, this chapter also touches on how law enforcement and criminal justice approaches towards WWUD have an impact on access to and use of existing services.

\section{Repression and Gender-based Stigma}

The repressive approach of drug policy in Russia and associated stigma was raised in most of the interviews as well as within human rights reports and cases. As a $\mathrm{CSO}$ worker stated, 'I believe that it is a very repressive system. Policies should be useful to all people. Russia denies this right and deprives people of choice when they use drugs'. Human rights organisations, such as Human Rights Watch, have also found that PWUD are criminalised, stigmatised and dehumanised through this drug policy approach (Human Rights Watch, 2004a, 2004b, 2007).

The repressive system of drug policy in Russia was also described by interviewees as employing particular gender-based stigma towards women who use drugs. The capacity or perceived capacity for motherhood that is part of many women's experience was seen as the root of such stigma. One CSO worker explained:

Women's role or the place of women [...] is worse than males, because there is a special stigma attached to women who use drugs because women are mothers... 
Playing the role of mother and custodian of family values does not go well along with drug dependence, drug use or alcohol use...If you at the same time turn yourself into this 'monster' who uses drugs, what kind of children can you have?

In a Russian CSO report submitted in the CEDAW 62nd session in 2015, such stigma was identified as a violation of Article 5 of the convention regarding state promoted stigma associated with a stereotypical understanding of maternity as a social function. The report argues that in Russia

the State officially declares a need for promoting intolerance towards drug use, which in practice leads to enormous stigma and discrimination against drug users. Society's stereotypical understanding of women's role as mothers aggravates such discrimination. (Public Mechanism for Monitoring Drug Policy Reform in the Russian Federation, 2015)

The overlapping discrimination that WWUD face on the basis of their gender and drug use has been documented as a widespread phenomenon and generally employs discourses of 'fallen or bad women and unfit mothers' (Jurgens, Csete, Amon, Baral, \& Beyrer, 2010, p. 479). Such stigma has multiple impacts on the lives of women who use drugs, but most notably it creates a barrier to health and social services and is frequently utilised to terminate parental rights.

\section{Extrajudicial Police Practices and Violence}

Turning from broader gender-based discrimination within the framework of Russian drug policy and towards the actual behaviours of police, extrajudicial practices and violence towards WWUD were brought up extensively by CSO workers. Many discussed these incidences as common place and common knowledge as they occur so frequently. Examples of extrajudicial practices included planting drugs on women who use drugs, police forcing WWUD to sell drugs on their behalf, entrapment and demands of bribes or sexual favours. Mention of violence specifically towards WWUD included physical violence and sexual violence, such as beatings, harassment or rape.

Surveillance of PWUD, chiefly through the drug user registry, was identified as a method used to carry out extrajudicial arrests. A CSO worker shared that 'if you are on the drug registry and they know you were a user, they can just plant drugs on you, and it happens a lot of the time'. Surveillance and the drug user registry were also described as tools of extortion. As another CSO worker described:

They're [WWUD] afraid to use public transport because there are a lot of cameras and a lot of policemen. Well, and they have like marks, you know you usually see it on hands or somewhere, and they will be stopped by the police, and then they just look in their database. And then if they find that 
you've been arrested previously then they will extort money from you or sexual things, or they will detain you. They will do whatever they want.

Data gathered also demonstrated that extrajudicial police practices extend into the entrapment of women who use drugs. In two cases presented to the ECHR, Bannikova versus Russia and Shlyakhova versus Russia, women were pressured into selling drugs by individuals who they did not know to be law enforcement. In the case of Bannikova versus Russia:

The applicant alleged that the sale of cannabis which had led to her conviction had been initiated by FSB agents, who had harassed her into finding and selling them the drug, and that she had never before committed the offence of procurement of drugs and would not have done so but for their intervention. (ECHR, 2010)

In both cases, women had a history of drug use, although in neither case was there prior evidence or convictions for drug selling or trafficking. One CSO worker discussed during an interview that WWUD are often easy targets for law enforcement looking to improve arrest statistics. Other studies have confirmed that police do, in fact, target PWUD in order to meet their quotas (Rhodes et al., 2006, p. 915).

The ease at which law enforcement carry out extrajudicial practices towards WWUD extends into violence as well. While it was noted that all PWUD are prone to violence at the hands of police, many CSO workers brought up particular vulnerability and experiences of violence that WWUD experience. One CSO worker stated that:

Women are easy targets because they have kids and you can easily manipulate them and do almost anything... They use, basically, that women are less strong so they can rape them, they can beat them. There are cases like this and no one will report it because the police still cover for each other.

This demonstrates that women are not only especially vulnerable to coercion and violence from law enforcement, but that they also have little recourse to pursue justice. A Russian CSO report submitted to the CEDAW 48th session argued that police often utilise the punitive framework of drug laws in Russia

as justification to harass or abuse women who use drugs and/or are involved in sex work, to extort money from them or force them to provide sexual services, exposing women to physical and psychological violence. (Submission from civil society, 2010)

Evidence of extrajudicial policing practices and violence from police towards WWUD indicates that such behaviours by law enforcement are neither infrequent nor condemned by the Russian approach to drug policy. Interviewees found that 
in their work, police feel 'justified' in carrying out violent actions towards PWUD and that they will often 'cover for each other' to avoid consequences. One CSO worker described law enforcement as an 'incubator for torture habits' and went on to state that, in fact,

police never really recognise any harm that they are inflicting. They actually think that they are doing a good job both towards society because, well, they save society from drugs, from the scourge of drugs.

This emphasises the findings of previous research which has detailed the seemingly limitless power that law enforcement have over WWUD in the Russian Federation (Golichenko \& Chu, 2018).

\section{Discrimination Across the Criminal Justice System}

The discrimination that women experience under Russian drug policy does not end with police. Rather, within the court system and in prisons or penal colonies, WWUD face additional stigma and challenges. This includes harsher sentencing practices, lack of proper legal support and poor conditions in prison. It is crucial to note that approximately 40 per cent of women are incarcerated for drug-related offences, while only 20 per cent of the male prison population has been incarcerated for a drug-related crime (Public Mechanism for Monitoring Drug Policy Reform in the Russian Federation, 2015). While women account for less than 7 per cent of the incarcerated population in Russia, they account for 14 per cent of all Russians imprisoned for drug-related offences (Public Mechanism for Monitoring Drug Policy Reform in the Russian Federation, 2015). Keeping in mind that women account for less than one-third of the drug-using population in Russia, such data speaks to the disproportionate representation of women imprisoned for drug-related offences.

A report submitted to the UN General Assembly by Special Rapporteur on violence against women addressed the high rate of incarceration of WWUD in Russia. It set out:

Russian drug policies are severe; that police violence against female drug users is common; that the acquittal rate in drug cases is less than 5 per cent; that in about 70 per cent of cases the accused are sentenced without trial; and that the courts do not take into account the conditions that make women vulnerable to drug use (Manjoo, 2013).

A number of CSO workers echoed the fact that sentencing practices fail to consider the special circumstances of WWUD but often display gender-based discrimination in sentencing. One CSO worker argued that:

courts do not take into account the presence of young children... There is a stereotype that a woman is a mother and she does not have the right to 
use at all... How it can be when a man is using it [drugs], no one condemns him?'

Data demonstrate that, in many cases, courts are harsher on WWUD than men who use drugs. In 2013, it was found that of all women in Russia sentenced for drug-related offences, over 43 per cent of women were charged with drug trafficking and 22 per cent for 'particularly serious crimes'. Comparatively, in 2013 amongst men convicted of drug-related offences, only 25 per cent were sentenced for drug trafficking and 13 per cent for 'drug crimes considered particularly serious' (Public Mechanism for Monitoring Drug Policy Reform in the Russian Federation, 2010). The delineation between the crimes of drug possession and trafficking in Russia is quite narrow and such statistics indicate that women are disproportionately convicted of more serious drug-related crimes than men.

In addition to gender-bias sentencing practices, there are also gender-based behaviours that put women at risk of being convicted for more serious drugrelated crimes. One CSO worker provided the following example:

A woman who is kind of depending on a man... in terms of the drugs, to get access to and probably even to money and some protection - they often give something like an apartment. An apartment could be used for drug use purposes without even recognizing it... then she can be prosecuted for providing this apartment for drug use. This old drug den charge... would be in addition to drug possession, so that's another harsher sentence.

Such cases and the strict sentences that follow speak to the lack of consideration of gender-based social roles that women often occupy in relationships, and that they often use with a male partner. It is estimated that women are charged for operating a drug den and for crimes of complicity at nearly twice the rate of men (Public Mechanism for Monitoring Drug Policy Reform in the Russian Federation, 2015).

Poor treatment and conditions within Russian prisons is a widely known phenomenon. Such an environment is especially difficult for people who use injection drugs, who are at higher risk for HIV and Hepatitis $\mathrm{C}$ and need specialised medical care. These needs often go unmet. A CSO worker commented on the lack of services for those with HIV or Tuberculosis across prisons in Russia, stating that:

The situation with medicine in prison is getting much worse lately throughout Russia, absolutely. In the Nizhny Novgorod region, a lot of senior medical worker positions are currently not filled. Basically, there is a paramedic, there is a nurse and, at best, a physician and general practitioner. There are no narrow medical specialists at all.

The lack of available care in prisons also extends into the lack of gendersensitive services. Another CSO worker commented that 'women's prisons are worse than male ones because there is no individual approach to women'. The lack of gender-sensitive care includes basic things such as feminine hygiene needs, to more complex issues such as the inhumane conditions around giving birth 
while incarcerated. Another chief concern raised by CSO workers was the lack of rehabilitation, treatment and penal colonies that allowed for the possibility of children to remain with their mothers.

\section{Discussion}

These findings illustrate that, while all PWUD fall under a regime of 'social intolerance' within Russia, WWUD face particular stigma, violence and human rights violations within the criminal justice system. Gender stereotypes regarding the role of women in society, specifically their capacity or perceived capacity to bear children, fuel this stigmatisation and discrimination towards women who use drugs. Research on gender, drugs and drug policy has similarly found that gender stereotypes equating women with motherhood produce discourses and policies that stigmatise and negatively impact WWUD and often frames them as unfit, failed mothers (Campbell, 2000; Ettorre, 2007; Gómez, 1997; Zerai \& Banks, 2002). This indicates that it is not only negative views around PWUD but also negative views around women who deviate from gender norms that frame especially harsh policies and practices towards WWUD within the Russian criminal justice system.

The numerous forms of extrajudicial police practices that were described in interviews and reports, from unwarranted arrest to extortion, convey that police have a pattern of exploiting women who use drugs. While some of these practices are also encountered by men who use drugs, the additional stigma WWUD face, as well as increased vulnerabilities due to involvement in sex work or the presence of children make women 'easy' targets for extrajudicial policing practices. Other studies conducted in Russia have found similar evidence of the disproportionate impact that these practices have on women (Lunze et al., 2016; Sarang et al., 2010). This speaks to the need for police accountability and a revaluation of the unchecked punitive practices employed by law enforcement, and reforms to Russian drug policy that would move drug use and simple possession out of the criminal justice system entirely.

Gender-based violence towards WWUD also calls for greater scrutiny towards the practices of law enforcement in Russia. As the findings of this research reveal, there is a pattern of police perpetrated violence against women who use drugs. Other research conducted in Russia confirms the high frequency at which WWUD experience rape, sexual harassment and violence (Open Society Institute, 2009; Sarang et al., 2010). It has also been found that women who inject drugs and are living with HIV experience sexual violence from police at a rate three times the regional average for women experiencing non-partner sexual violence (Lunze et al., 2016, p. 5). This demonstrates the endemic nature of police perpetrated violence towards women who use drugs.

The negative and disparate gender-based impacts of drug policy enforcement in Russia are also evident across the broader criminal justice system and indicate an attitude that WWUD deserve harsher punishments. This is evidenced by the disproportionate sentences that WWUD receive as compared to men for similar drug-related crimes as well as the lack of sensitivity towards gender-based drug-using behaviours that put women at risk of more significant convictions. 
Other studies and reports have documented similar trends both regionally and globally (i.e. Iakobishvili, 2012; Manjoo, 2013). This phenomenon is due in large part to gender-based stereotypes that women are not only mothers but also the moral keepers of society. It has been theorised that

drug use by women is often regarded as a deviation of their social stereotypes, in which they are seen as unfeminine. This contrasts with men who are expected to be aggressive. (Mountain, 2013, p. 106)

In this sense, WWUD are framed with heightened criminality not only for their drug use but also for breaking from traditional social roles.

While this research focusses primarily on the treatment of WWUD within the criminal justice system, it is important to mention the impacts that such conditions have on access to health and social services. Punitive policing practices in Russia have been found to 'perpetuate fear and terror, internalised stigma and a sense of helplessness and fatality, especially among women' (Lunze et al., 2016, p. 2). This is associated with increased risk behaviours. For example, PWUD are often afraid to carry syringes with them and therefore use drugs with a shared syringe at the point of purchase (Sarang et al., 2010, p. 815). Discrimination from police has been identified as a barrier to accessing HIV services amongst PWUD. Sexual violence from police has also been reported by human rights bodies as a contributor towards the reluctance of WWUD to access those limited harm reduction services that do exist in Russia (Lunze et al., 2016; Rhodes et al., 2006). For this reason, the practices of police and the criminal justice system towards WWUD cannot be understood only as a violation of human rights, but also as a factor contributing to negative public health outcomes and a deterrent to accessing the few treatment and harm reduction services that exist in Russia.

\section{Conclusion}

Drug policies in Russia employ a range of punitive practices to punish and exert social control over PWUD. The negative impacts that such an approach has on PWUD is multiplied for women who use drugs, who live at the intersection of two oppressed identities: woman and drug user. The considerable power and authority that the police and courts in Russia have over this population are manifested through unchecked exploitation, violence and discrimination. Officials are not held accountable and, instead, their actions are fortified by a punitive drug policy framework that has zero tolerance for women who use drugs. This system and its actors infringe on the basic human rights of these women and result in significant public health consequences. Within this environment, the efforts of CSOs working to support WWUD are extremely noteworthy. While the resources and freedoms of such organisations pale in comparison to the seemingly limitless power of the state and its actors, they are there, on the ground, providing support and services. Civil society actors have also utilised women's and human rights mechanisms, such as CEDAW and ECHR, to shed light on a population and situation that is stigmatised and largely overlooked. As their work indicates, there is a significant need for drug policies in Russia to be reformed, positioning gender-sensitivity, human rights, and the protection of dignity and health at the centre. 